\title{
Penerapan Panel Surya sebagai Sumber Energi Listrik Alternatif pada Gedung Fakultas Teknik Universitas Teuku Umar
}

\author{
T. M. Azis Pandria ${ }^{1 *}$, Nissa Prasanti ${ }^{2}$ \\ ${ }^{1,2}$ Program Studi Teknik Industri, Fakultas Teknik, Universitas Teuku Umar \\ *Koresponden email: azispandria@utu.ac.id
}

Diterima: 7 September 2021

Disetujui: 9 Oktober 2021

\begin{abstract}
After turning into a state university, Universitas Teuku Umar continues to improve a number of infrastructures including the addition of a number of buildings. Currently the only source of electricity used to run all facilities in the building only from PLN, so that in the face of obstacles such as blackouts, suspension of electricity supply, or other technical constraints will result in the cessation of all activities so that it has an impact on the decline in the performance of the Faculty of Engineering in general. Research on the application of solar panels installed on the roof of the building (rooftop) as Building Applied Photovoltaic (BAPV) was conducted. The purpose of the study is to find out the number of solar panels and other devices needed for the application of PLTS in the Faculty of Engineering Building. PVsyst V7.2 software It is used to obtain daily solar radiation values at the locations reviewed. The existing Total Energy (TE) value calculation method is used to determine the capacity of solar panels and other supporting equipment. Results show an existing TE value of $20,422 \mathrm{Wh} /$ day or equivalent to $20,422 \mathrm{kWh} /$ day. Based on te value the number of solar panels needed as much as 33 units of capacity $120 \mathrm{Wp}$, Solar Charge Controller (PWM) 12 V-250 A 1 unit, VRLA Gel Battery Brand VOS 12V - 150 Ah 41 units, Inverter Pure Sine Wave (PSW) Split Phase Inverter Charger Series power 1-6 KW 1 unit.
\end{abstract}

Keywords: solar panel, solar energy, renewable energy, EBT, Universitas Teuku Umar

\begin{abstract}
Abstrak
Pasca penegerian, Universitas Teuku Umar terus membenahi sejumlah infrastruktur termasuk penambahan sejumlah gedung. Saat ini satu - satunya sumber energi listrik yang digunakan untuk menjalankan semua fasilitas pada gedung hanya dari PLN, sehingga bila terjadi kendala seperti pemadaman, terhentinya pasokan energi listrik, atau kendala teknis lainnya akan berakibat pada terhentinya seluruh kegiatan sehingga berdampak pada penurunan kinerja Fakultas Teknik secara umum. Penelitian terhadap penerapan panel surya yang dipasang pada atap gedung (rooftop) sebagai Building Applied Photovoltaic (BAPV) dilakukan. Tujuan penelitian guna mengetahui jumlah panel surya dan perangkat lainnya yang diperlukan untuk penerapan PLTS pada Gedung Fakultas Teknik. Aplikasi PVsyst V7.2. digunakan untuk mendapatkan nilai radiasi matahari harian pada lokasi yang ditinjau. Metode perhitungan nilai Total Energi (TE) eksisting digunakan untuk menentukan kapasitas panel surya dan peralatan pendukung lainnya. Hasil menunjukkan nilai TE eksisting $20.422 \mathrm{Wh} /$ hari atau setara 20,422 $\mathrm{kWh} /$ hari. Berdasarkan nilai TE jumlah panel surya yang dibutuhkan sebanyak 33 unit kapasitas $120 \mathrm{Wp}$, Solar Charge Controller (PWM) 12 V250 A 1 unit, Baterai VRLA Gel Merk VOS 12V - 150 Ah 41 unit, Inverter Pure Sine Wave (PSW) Split Phase Inverter Charger Series daya 1-6 KW 1 unit.
\end{abstract}

Kata Kunci: panel surya, energi listrik, energi terbarukan, EBT, Universitas Teuku Umar

\section{Pendahuluan}

Letak Indonesia yang berada pada garis khatulistiwa memberikan keuntungan tersendiri, terutama intensitas radiasi matahari dengan nilai rata-rata mencapai $4,8 \mathrm{kWh} / \mathrm{m} 2$ per hari di seluruh wilayah Indonesia [1]. Kabupaten Aceh Barat berada dekat dengan garis khatulistiwa, atau disisi utara dari garis ekuator dan memiliki intensitas penyinaran matahari cukup tinggi. Aceh Barat sangat diuntungkan dengan kondisi ini, dimana intensitas matahari tersebut dapat dimanfaatkan untuk mengembangkan sistem pembangkit listrik tenaga matahari atau PLTS. Pemanfaatan energi surya atau matahari dapat dijadikan solusi untuk mencukupi kebutuhan energi listrik terutama dari sumber energi terbarukan. Namun hingga saat ini potensi radiasi matahari yang berlimpah ini belum dimanfaatkan secara optimal, terutama di wilayah Aceh Barat [2].

Perkembangan kebutuhan akan energi listrik yang terus meningkat di Aceh Barat terutama pada pusat-pusat layanan umum seperti rumah sakit, perhotelan, pusat perbelanjaan dan fasilitas pendidikan 
seperti kampus [3]. Konsumsi energi yang dibutuhkan cukup besar dan harus dapat diakomodir oleh penyedia layanan energi listrik seperti PT. PLN. Konsumsi energi listrik dengan karakteristik operasional 24 jam menuntut tersedianya pasokan energi yang memadai. Selama ini selaku operator penyedia listrik PT. PLN telah membangun fasilitas pembangkit listrik untuk menyuplai kebutuhan konsumen dengan menggunakan pembangkit yang mengonsumsi energi fosil (BBM) sebagai sumber energi primernya [4]. Untuk jangka panjang penggunaan energi fosil tidak lagi diprioritaskan, kondisi ini sejalan dengan peta rencana pengembangan energi nasional yang telah digariskan pemerintah [5]. Agar dapat mencukupi kebutuhan akan energi listrik, konsumen atau pihak pengguna energi membutuhkan energi listrik secara kontinu dan handal [6]. Pemanfaatan energi surya sebagai sumber listrik dapat dimulai dari lingkungan terbatas, seperti memanfaatkan sistem Building Applied Photovoltaic (BAVP) yang dipasang di rooftop pada fasilitas hotel, rumah sakit dan kampus [7].

Fakultas Teknik Universitas Teuku Umar merupakan salah satu kampus yang berada di wilayah Aceh Barat dengan jumlah pertumbuhan mahasiswa yang cukup besar selama ditetapkan sebagai salah satu Universitas Negeri pada Tahun 2014 silam [8]. Pasca penegerian, Universitas Teuku Umar terus berbenah terutama dari sisi infrastruktur. Umumnya pembenahan tersebut dilakukan di berbagai bidang, seperti peningkatan kualitas SDM, infrastruktur dan administrasi. Khusus dibidang infrastruktur, penambahan gedung untuk memenuhi fasilitas perkuliahan menjadi prioritas yang dilakukan pasca penegerian. Pertambahan jumlah gedung berimbas pada meningkatnya konsumsi energi listrik untuk menunjang semua proses akademik di setiap fakultas. Fakultas Teknik merupakan salah satu fakultas di lingkungan Universitas Teuku Umar yang selama ini menggunakan fasilitas Gedung Laboratorium Terpadu sebagai pusat akademis dan perkuliahan.

Untuk mencukupi kebutuhan energi listrik, Gedung Fakultas Teknik menggunakan sumber energi listrik dari PT. PLN sebagai satu-satunya sumber primer untuk menjalankan semua fasilitas pada gedung tersebut. Kendala yang sering dialami adalah saat terjadi pemadaman atau terhentinya pasokan energi listrik dari PLN, baik yang diakibatkan oleh gangguan alam maupun kerusakan lainnya. Semua peralatan yang menggunakan energi listrik menjadi terhenti bekerja karena ketiadaan listrik. Kondisi yang tidak menguntungkan ini, terutama bagi konsumen menjadi kendala yang dapat mempengaruhi kinerja Fakultas Teknik secara umum. Penggunaan panel surya sebagai sumber Energi Baru Terbarukan (EBT) menjadi salah satu sumber energi alternatif yang diharapkan mampu memenuhi kebutuhan energi listrik pada gedung Fakultas Teknik, Universitas Teuku Umar. Aplikasi panel surya yang dapat dilakukan seperti pemasangan pada atap atau rooftop, dimana panel surya diletakkan pada atap gedung. Pemasangan dengan model ini bertujuan untuk memanfaatkan ruang kosong pada atap bangunan atau yang lebih dikenal dengan Building Applied Photovoltaic (BAPV) [7].

Radiasi matahari dapat dimanfaatkan sebagai salah satu sumber energi listrik yang bersumber dari energi baru terbarukan (EBT), dan panel surya mengubah radiasi tersebut menjadi energi listrik [9]. Berdasarkan penerapannya sistem penempatan panel surya sebagai pembangkit listrik dibagi menjadi dua model, pertama yang disebut sebagai solar park (panel surya yang diletakkan diatas permukaan tanah) dan rooftop photovoltaic system (panel surya diletakkan diatas atap bangunan)[10]. Berdasarkan instalasi, panel surya dibedakan menjadi off grid system dan on grid system connected. Panel surya off grid system identik dengan stand-alone system, sedangkan on grid system terhubung dengan grid utility (jaringan eksisting PLN)[11]. Panel surya dengan konfigurasi baterai dan peralatan pendukung lainnya dikenal sebagai Pembangkit Listrik Tenaga Surya (PLTS), dan merupakan suatu jenis pembangkit listrik yang bekerja dengan prinsip mengonversi cahaya matahari menjadi energi listrik, dan proses konversi ini terjadi pada panel surya yang terdiri dari sejumlah sel surya[12]. Panel surya memanfaatkan cahaya matahari dan mengubahnya menjadi listrik DC (Direct Current) dan dapat diubah kembali menjadi listrik AC (Alternating Current). PLTS di ibaratkan sebagai catu daya yang dirancang untuk kebutuhan listrik skala kecil hingga besar dengan model stand-alone maupun hybrid [1].

Tujuan penelitian ini adalah (1) mengetahui hasil evaluasi jumlah daya listrik eksisting yang dibutuhkan pada Gedung Fakultas Teknik, Universitas Teuku Umar, (2) menentukan jumlah panel surya dan peralatan aksesoris instalasi lainnya yang dibutuhkan untuk mendukung kebutuhan daya listrik pada Gedung Fakultas Teknik, Universitas Teuku Umar, dan (3) menentukan model instalasi panel surya yang sesuai untuk diterapkan pada Gedung Fakultas Teknik, Universitas Teuku Umar.

\section{Metode Penelitian}

\section{Tempat dan Waktu Penelitian}

Penelitian ini dilakukan pada Gedung Lama Fakultas Teknik Universitas, Teuku Umar, Desa Alue Peunyareng, Kecamatan Meureubo, Kabupaten Aceh Barat. Penelitian dilaksanakan dalam kurun waktu 4 
bulan. Jenis penelitian bersifat deskriptif dengan metode eksperimen dan analisis data. Penelitian ini menggunakan data primer dan juga data sekunder. Data primer penelitian diperoleh dari proses pengamatan langsung di lapangan dengan data yang diperoleh berupa layout Gedung Fakultas Teknik dan daya listrik eksisting yang digunakan pada gedung tersebut. Data sekunder penelitian ini merupakan data intensitas radiasi matahari, suhu, kondisi atmosfer, pada titik lokasi sesuai koordinat Gedung Fakultas Teknik, Universitas Teuku Umar yang diperoleh dari Software Pvsyst [13]. Adapun lokasi dan gedung tempat penelitian dilakukan dapat dilihat pada Gambar 1 dan Gambar 2.

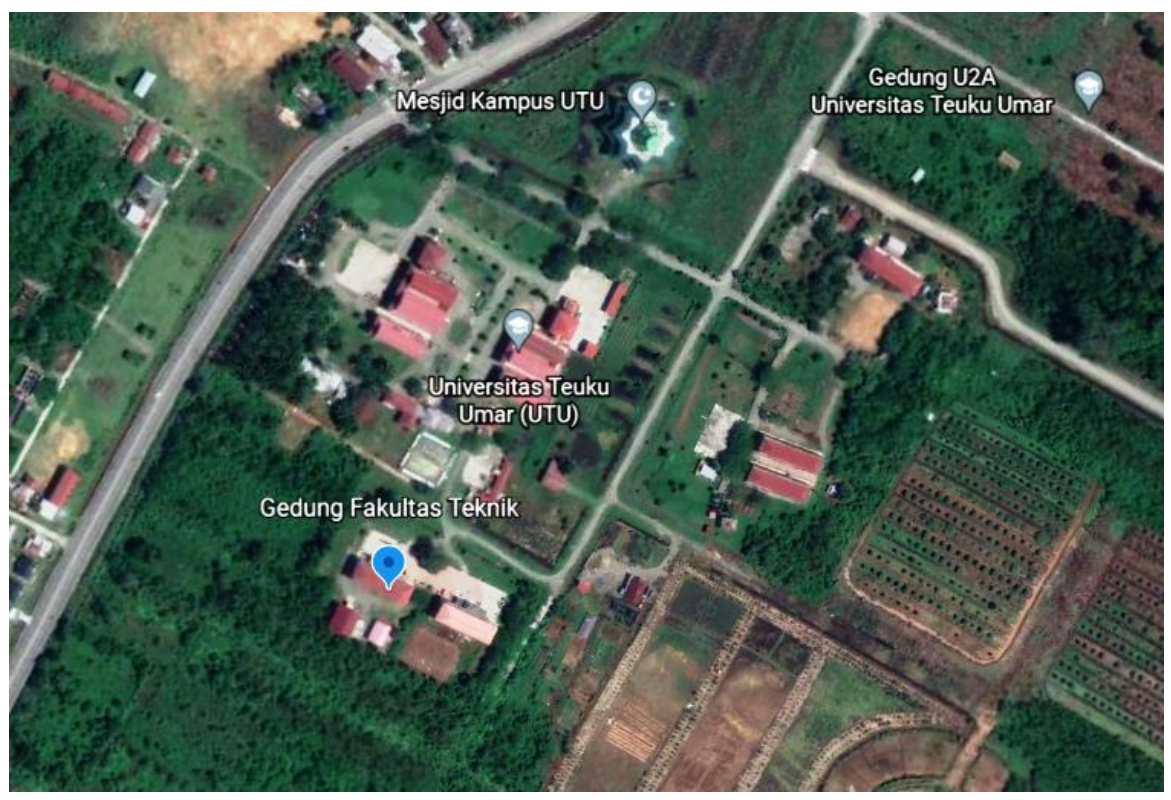

Gambar 1. Lokasi Penelitian

Sumber: Solar Global Atlas, 2021
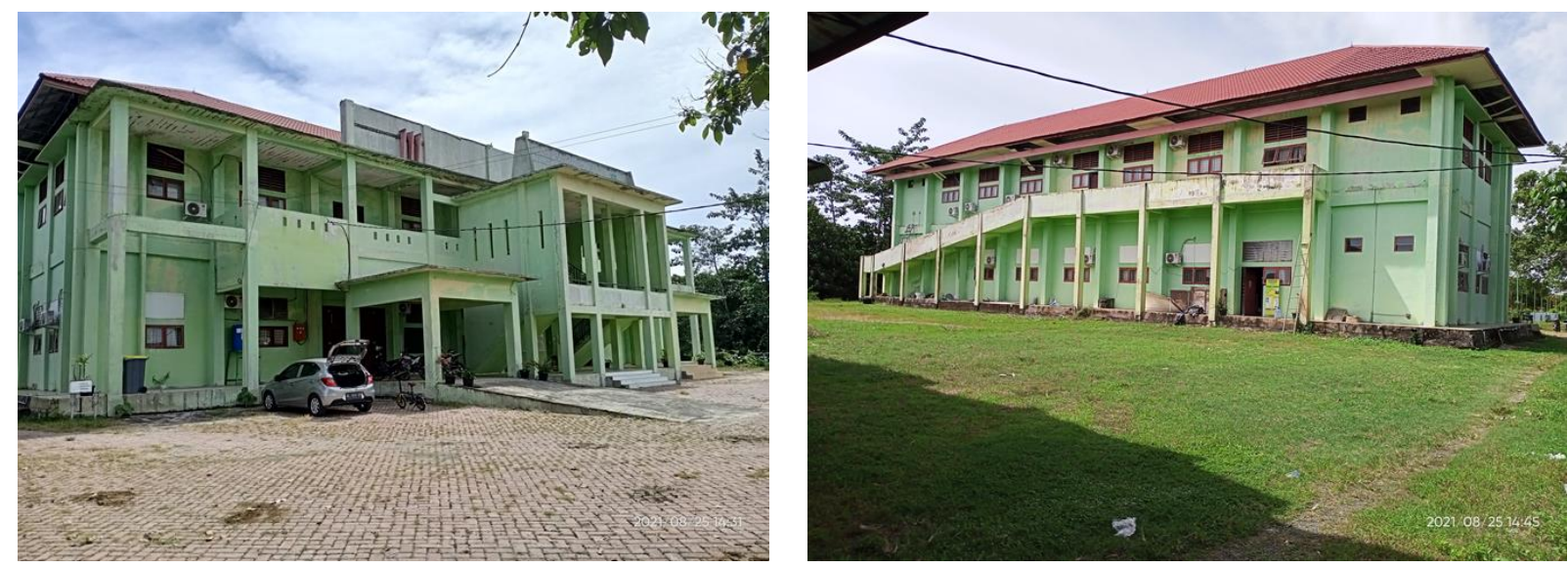

Gambar 2. Tampak depan dan belakang gedung Sumber: Foto penelitian, 2021

\section{Alat dan Bahan}

Beberapa alat dan bahan yang digunakan dalam penelitian ini diantaranya dapat dilihat pada Tabel 1.

Tabel 1. Alat dan bahan yang digunakan

\begin{tabular}{ll}
\hline \multicolumn{1}{c}{ Nama Alat dan Bahan } & \multicolumn{1}{c}{ Spesifikasi Teknis } \\
\hline Panel Surya Merk GH Solar & Model: GH120P-18 (Polycristalline) \\
& Vmax $\left(\mathrm{V}_{\mathrm{mp}}\right) 18,4 \mathrm{~V}$ \\
& $\left.\mathrm{Imax}_{(\mathrm{mp}}\right) 6,53 \mathrm{~A}$ \\
& $\mathrm{~V}_{\mathrm{oc}}: 22,6 \mathrm{~V}$ \\
& $\mathrm{I}_{\mathrm{sc}}: 6,98 \mathrm{~A}$ \\
Solar Charge Controller (SCC) Merk MUST & Tegangan $: 12 / 24 / 36 / 48 \mathrm{~V}$ \\
& Arus $: 60 / 80 / 100 / 150 / 250 \mathrm{~A}$ \\
& Jenis : MPPT \\
\hline
\end{tabular}




\begin{tabular}{ll}
\hline Baterai Merk VOS & Jenis : VRLA Gel tegangan :12V \\
& Kapasitas :150 Ah \\
Inverter Merk MUST Type EP3300 TLV & Low Frequency Pure Sine Wave (PWM) \\
& Split Phase Inverter \\
& Charger Series daya 1-6KW \\
\hline
\end{tabular}

Sumber: Pengolahan data, 2021

\section{Prosedur penelitian}

Tahapan penelitian dimulai dengan melakukan studi pendahuluan berupa studi lapangan (observasi gedung tempat penelitian) dan studi literatur sehingga diperoleh masalah yang akan uraikan pada latar belakang penelitian hingga tujuan dari penelitian ini [14]. Selanjutnya dilakukan pengumpulan data primer dan juga data sekunder. Data primer dalam penelitian ini diperoleh melalui observasi lapangan, sedangkan data sekunder diperoleh dari software yang mendukung penelitian ini. Prosedur penelitian akan menjelaskan tahapan atau langkah-langkah yang dilakukan dalam penelitian. Adapun prosedur penelitian ini secara garis besar dapat dilihat pada Gambar 3.

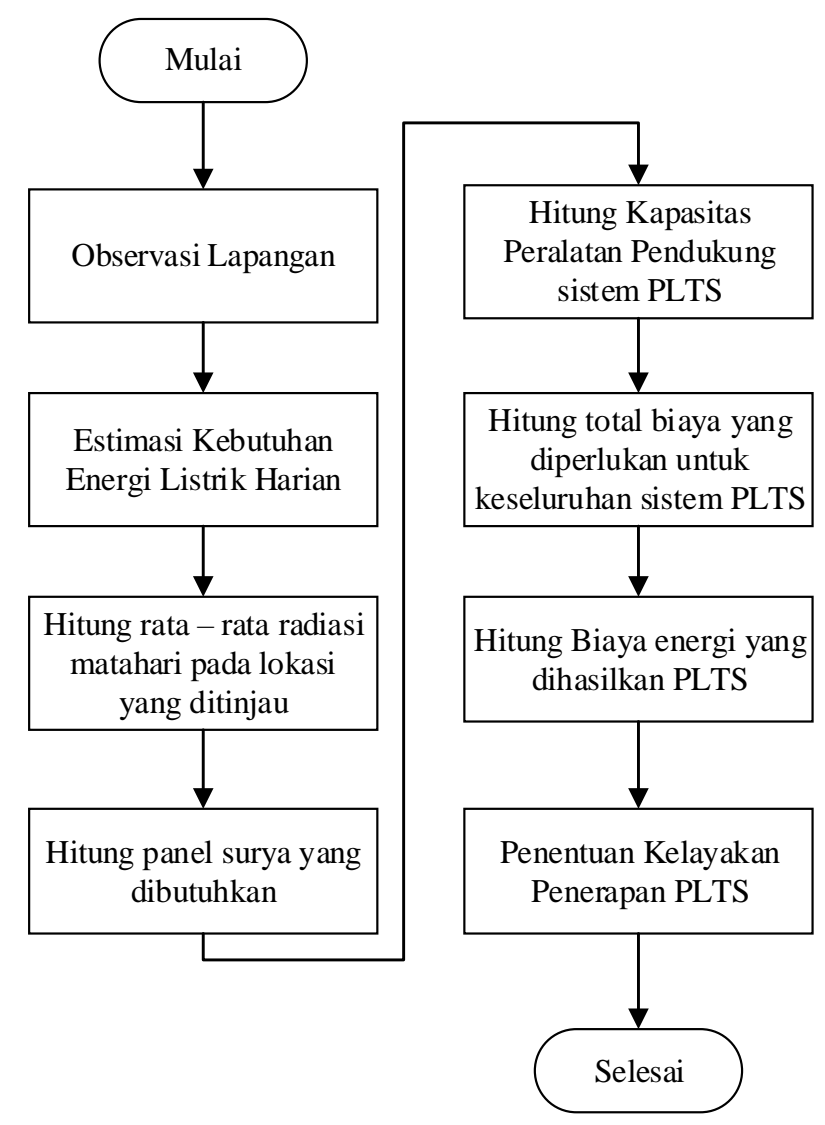

Gambar 3. Prosedur Penelitian

Sumber: Pengolahan data, 2021

Berdasarkan Gambar 3, prosedur penelitian ini dapat dijelaskan sebagai berikut.

1. Observasi lapangan dilakukan untuk melihat kondisi gedung yang rencananya akan ditempatkan panel surya.

2. Estimasi kebutuhan energi listrik harian diperlukan untuk melihat seberapa besar penggunaan penggunaan energi listrik pada gedung. Kebutuhan jumlah Energi dapat dilihat dari seberapa besar daya yang digunakan olah beban eksisting pada gedung.

3. Nilai rata-rata radiasi matahari pada lokasi gedung penelitian akan diperoleh dari software PVsyst Versi 7.2.4. Data tersebut berasal dari meteonorm 8.0 yang memberikan beberapa jenis radiasi seperti Global Horizontal, diffuse Horizontal, Extrateresterial, dan beberapa data pendukung lainnya seperti nilai Clearness Index, Ambient Temperature dan Wind Velocity.

4. Jumlah panel surya yang dibutuhkan akan dihitung berdasarkan nilai Total Energi (TE) per hari dengan menggunakan persamaan 1 : 


$$
\Sigma_{p}=\frac{T E}{\text { cap.panel } x P S H}
$$

5. Beberapa kapasitas dari peralatan pendukung sistem PLTS akan dihitung untuk mendapatkan keakuratan nilai sehingga tidak mengalami kegagalan sistem ke depannya. Adapun peralatan tersebut seperti Solar Charge Controller (SCC), baterai, dan inverter.

a) SCC merupakan bagian yang cukup penting dalam instalasi PLTS dan juga dengan penyebutan yang beragam, diantaranya Battery Control Unit (BCU), Battery Control Regulator (BCR) dan SCC itu sendiri. Fungsi utama dari SCC adalah untuk melindungi dan mengatur pengisian baterai secara otomatis, hal ini bertujuan untuk mengoptimalkan sistem dan menjaga baterai agar memiliki masa pakai maksimal [15].

b) Perhitungan terhadap baterai dilakukan untuk mengetahui seberapa banyak jumlah baterai dan kapasitas daya yang dibutuhkan untuk menangani beban berdasarkan nilai konsumsi energi. Penentuan jumlah dan kapasitas baterai sangat berpengaruh terhadap sistem PLTS dan dihitung menggunakan persamaan 2:

$$
\sum_{B}=\left(\frac{T E}{\text { cap.bat } x \text { DoD }}\right) x \text { outonomy.day }
$$

c) Inverter merupakan perangkat elektronik yang digunakan untuk mengubah tegangan Direct Current (DC) menjadi tegangan Alternating Current (AC).

6. Energi keluaran yang dihasilkan panel surya akan dihitung menggunakan asumsi bahwa radiasi matahari yang diterima panel yaitu selama 12 jam per hari dengan nilai maksimal.

7. Model diagram rangkaian PLTS yang akan digunakan yaitu menggunakan sistem off grid, yaitu sistem kelistrikan tidak terhubung ke jaringan listrik perusahaan listrik negara, atau sepenuhnya akan bergantung pada penggunaan PLTS.

8. Total biaya investasi sistem PLTS yang akan dibangun pada Gedung Fakultas Teknik dihitung berdasarkan harga persatuan peralatan yang digunakan.

9. Penentuan kelayakan penerapan PLTS dinilai berdasarkan total nilai investasi yang dikeluarkan untuk instalasi sistem PLTS off grid pada gedung Fakultas Teknik dengan perbandingan nilai penggunaan energi dari PLN saat ini, dan masih dalam katagori layak untuk perkiraan penggunaan dalam jangka waktu 20 tahun.

\section{Hasil dan Pembahasan}

\section{Estimasi Kebutuhan Energi Listrik Harian}

Hasil observasi yang telah dilakukan pada gedung Fakultas Teknik, Universitas Teuku Umar, diperoleh beberapa data diantaranya jenis beban, lama waktu operasional beban dan besaran daya listrik yang digunakan seperti ditampilkan pada Tabel 2 (beban disimulasikan dengan jumlah tunggal).

Tabel 2. Data beban eksisting pada gedung Fakultas Teknik

\begin{tabular}{lrrr}
\hline \multicolumn{1}{c}{ Jenis Beban } & $\begin{array}{c}\text { Daya/unit } \\
\text { (Watt) }\end{array}$ & $\begin{array}{r}\text { Waktu Operasional } \\
\text { (Jam) }\end{array}$ & Energi (Wh) \\
\hline Lampu TL fluorescent 40 Watt & 40 & 12 & 480 \\
Air Conditioner 2 PK 1.740 W & 1.740 & 10 & 17.400 \\
Dispenser 180 W & 180 & 5 & 900 \\
Komputer PC 90 W & 90 & 10 & 900 \\
Switch Multi port 24 Chanel 8 W & 8 & 24 & 192 \\
Printer 10 W & 10 & 5 & 50 \\
Pompa Air Shimizu 125 W & 125 & 4 & 500 \\
\hline \multicolumn{2}{c}{ Total Energi (TE) } \\
\hline
\end{tabular}

Sumber: Pengolahan data, 2021

Nilai Total Energi (TE) yang ditampilkan pada Tabel 2 merupakan konsumsi energi harian sebesar $20.422 \mathrm{Wh} /$ hari atau setara 20,422 kWh/hari. Saat melakukan perancangan penerapan panel surya dengan sistem PLTS harus diperhitungkan juga factor losses. Factor losses bisa diakibatkan oleh berbagai faktor seperti sistem instalasi kabel yang panjang, kehilangan tegangan pada konektor dan efisiensi dari panel surya itu sendiri dan juga tingkat radiasi matahari. Untuk itu perlu ditambahkan nilai daya sebesar $20 \%$ dari nilai awal $(20.422 \times 20 \%=24.506)$. 


\section{Nilai Rata-Rata Radiasi Matahari pada Lokasi Gedung}

Berikut beberapa data radiasi matahari pada lokasi gedung Fakultas Teknik sesuai koordinat 4.144 LU, 96.196 BT seperti pada Tabel 3 dan Tabel 4.

Tabel 3. Nilai rata-rata harian radiasi matahari pada lokasi gedung

\begin{tabular}{lccc}
\hline \multicolumn{1}{c}{ Bulan } & $\begin{array}{c}\text { Global } \\
\left(\mathrm{kWh} / \mathrm{m}^{2} / \text { day }\right)\end{array}$ & $\begin{array}{c}\text { Diffuse } \\
\left(\mathrm{kWh} / \mathrm{m}^{2} / \text { day }\right)\end{array}$ & $\begin{array}{c}\text { Temperatur } \\
\left({ }^{\circ} \mathrm{C}\right)\end{array}$ \\
\hline Januari & 5,80 & 2,06 & 26,9 \\
Februari & 6,07 & 2,44 & 27,3 \\
Maret & 5,92 & 2,61 & 27,7 \\
April & 5,56 & 2,65 & 27,7 \\
Mei & 5,49 & 2,55 & 28,4 \\
Juni & 5,04 & 2,56 & 28,1 \\
Juli & 5,62 & 2,53 & 28,2 \\
Agustus & 5,08 & 2,67 & 28,0 \\
September & 5,06 & 2,70 & 27,2 \\
Oktober & 4,63 & 2,65 & 27,2 \\
November & 5,08 & 2,29 & 26,5 \\
Desember & 4,93 & 2,33 & 26,8 \\
\hline
\end{tabular}

Sumber: Meteonorm 8.0, 2021

Tabel 4. Nilai rata-rata bulanan radiasi matahari pada lokasi gedung

\begin{tabular}{lccc}
\hline \multicolumn{1}{c}{ Bulan } & $\begin{array}{c}\text { Global } \\
\left(\mathrm{kWh} / \mathrm{m}^{2} / \text { day }\right)\end{array}$ & $\begin{array}{c}\text { Diffuse } \\
\left(\mathrm{kWh} / \mathrm{m}^{2} / \text { day }\right)\end{array}$ & $\begin{array}{c}\text { Temperatur } \\
\left({ }^{\circ} \mathrm{C}\right)\end{array}$ \\
\hline Januari & 179,7 & 63,9 & 26,9 \\
Februari & 170,0 & 68,4 & 27,3 \\
Maret & 183,6 & 81,0 & 27,7 \\
April & 166,7 & 78,4 & 27,7 \\
Mei & 170,3 & 79,0 & 28,4 \\
Juni & 151,3 & 76,8 & 28,1 \\
Juli & 174,1 & 78,3 & 28,2 \\
Agustus & 157,6 & 82,7 & 28,0 \\
September & 151,9 & 81,0 & 27,2 \\
Oktober & 143,5 & 82,2 & 27,2 \\
November & 152,5 & 68,7 & 26,5 \\
Desember & 152,8 & 72,3 & 26,8 \\
\hline
\end{tabular}

Sumber: Meteonorm 8.0, 2021

\section{Perhitungan Jumlah Panel Surya yang dibutuhkan}

Berdasarkan data beban eksisting yang ditampilkan pada Tabel 2, diketahui Total Energi (TE) harian pada Gedung Fakultas Teknik dengan memperhitungkan factor losses sebesar $24.506 \mathrm{Wh} / \mathrm{hari}$ atau setara dengan 24,506 kWh/hari. Berdasarkan perhitungan menggunakan persamaan 1, diperoleh jumlah sebanyak 33 unit panel surya dengan kapasitas daya 120 Wp. Nilai Peak Sun Hours (PSH) berpatokan pada nilai lokasi gedung Fakultas Teknik yang berada di kawasan Alue Peunyareng. Untuk mengetahui besaran nilai tegangan yang dihasilkan panel surya dengan kapasitas $120 \mathrm{Wp}$ pada saat PSH, dilakukan pengukuran langsung pada lokasi yang ditentukan seperti tampak pada Gambar 4.
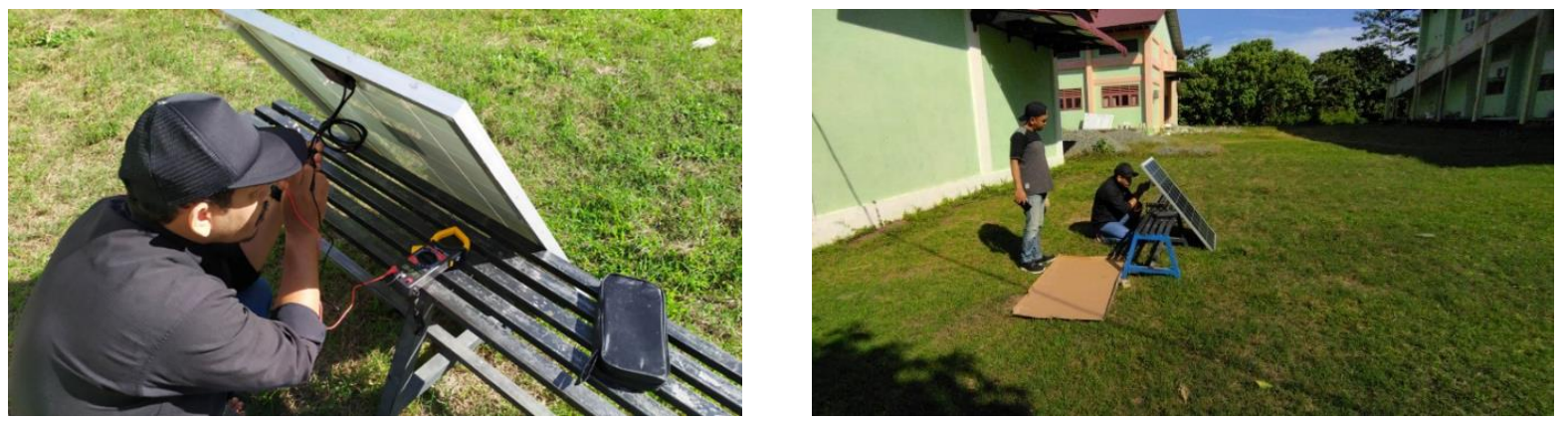

Gambar 4. Proses Pengukuran Tegangan Keluaran saat Peak Sun Hours (PSH)

Sumber: Foto penelitian, 2021 
Hasil pengukuran langsung diketahui bahwa nilai rata-rata tegangan pada saat PSH di lokasi yang dihasilkan panel surya sebesar 21 Volt, atau mendekati nilai tegangan maksimum panel surya pada kondisi Open Circuit Voltage (VOC) sebesar 22,6 Volt. Panel surya yang digunakan pada saat pengukuran di lapangan menggunakan jenis polycrystalline model GH120P-18 dengan kapasitas $120 \mathrm{Wp}$.

Perhitungan Kapasitas Peralatan Pendukung Sistem PLTS

Penelitian ini menggunakan SCC jenis MPPT karena sistem yang direncanakan pada penelitian ini memiliki daya cukup besar. Penentuan nilai SCC jenis MPPT yang digunakan pada penelitian ini menggunakan daya 250 Ampere. Nilai ini digunakan dengan pertimbangan daya SCC harus lebih tinggi dibanding nilai daya maksimum sistem sebesar 215 Ampere.

Berdasarkan perhitungan dengan menggunakan persamaan 2, nilai TE menggunakan nilai total energi yang telah ditambahkan dengan nilai losses sebesar $20 \%$ sebesar $24.506 \mathrm{Wh} / \mathrm{hari}$. Nilai kapasitas baterai menggunakan nilai $900 \mathrm{Ah}$ yang diperoleh dari tegangan $12 \mathrm{~V}-150 \mathrm{Ah}$ yang dikalikan dengan nilai Deep of Charge (DoD) 50\% = 0,5. Untuk nilai outonomy day menggunakan nilai 3 hari, dan nilai tersebut dianggap sudah cukup ideal untuk nilai backup. Hasil perhitungan tersebut diperoleh 13,61, nilai ini kemudian dikalikan 3 (outonomy day) sehingga menjadi 40.8 dibulatkan menjadi 41 unit baterai dengan kapasitas daya $150 \mathrm{Ah}$. Jenis baterai yang digunakan adalah VRLA Gel Merk VOS 12V - 150 Ah. Kelebihan baterai ini tahan terhadap kondisi charging berulang kali, over charging dan juga tahan terhadap guncangan dari luar.

Berdasarkan jenis dan variasi nilai beban pada gedung Fakultas Teknik, maka digunakan inverter Low Frequency Pure Sine Wave Split Phase Inverter Charger Series daya 1-6KW dengan kode EP3300 TLV. Pemilihan kapasitas inverter berpedoman pada kapasitas baterai sebanyak 33 unit sebesar 215,49 A, dan jika di konversikan ke dalam Watt menjadi $2.58 \mathrm{~kW}$.

\section{Energi Keluaran yang dihasilkan Panel Surya}

5.

Hasil perhitungan terhadap energi keluaran yang dihasilkan oleh panel surya dapat dilihat pada Tabel

Tabel 5. Energi keluaran panel surya

\begin{tabular}{|c|c|}
\hline \multirow{2}{*}{\multicolumn{2}{|c|}{$\begin{array}{l}\text { Spesit1kas1 Panel Surya } \\
\text { Tipe GH120P-18 }\end{array}$}} \\
\hline & \\
\hline - Rated Maximum Power (Pm) $120 \mathrm{~W}$, & - Daya/hari $=119,6$ Watt (1 panel) \\
\hline Voltage at Pmax (Vmp) 18,4 V, & - Daya total/hari $=3.946$ Watt (33 panel) \\
\hline - Current at Pmax (Imp) 6,5 A & - Energi total $/$ hari $=47.361(\mathrm{Wh} / \mathrm{hari})(33$ panel $)$ \\
\hline - Open Circuit Voltage (Voc) 22,6 V & \\
\hline
\end{tabular}

Nilai keluaran tersebut dihitung berdasarkan asumsi panel dapat menerima radiasi matahari selama 12 jam per hari dengan nilai maksimal.

\section{Model Diagram Rangkaian PLTS Off Grid yang digunakan}

Model diagram rangkaian panel surya yang tersusun dalam sistem PLTS pada gedung Fakultas Teknik menggunakan system off grid. Kondisi ini sesuai dengan simulasi perhitungan daya yang telah dilakukan dan system off grid yang digunakan seperti tampak pada Gambar 5. 


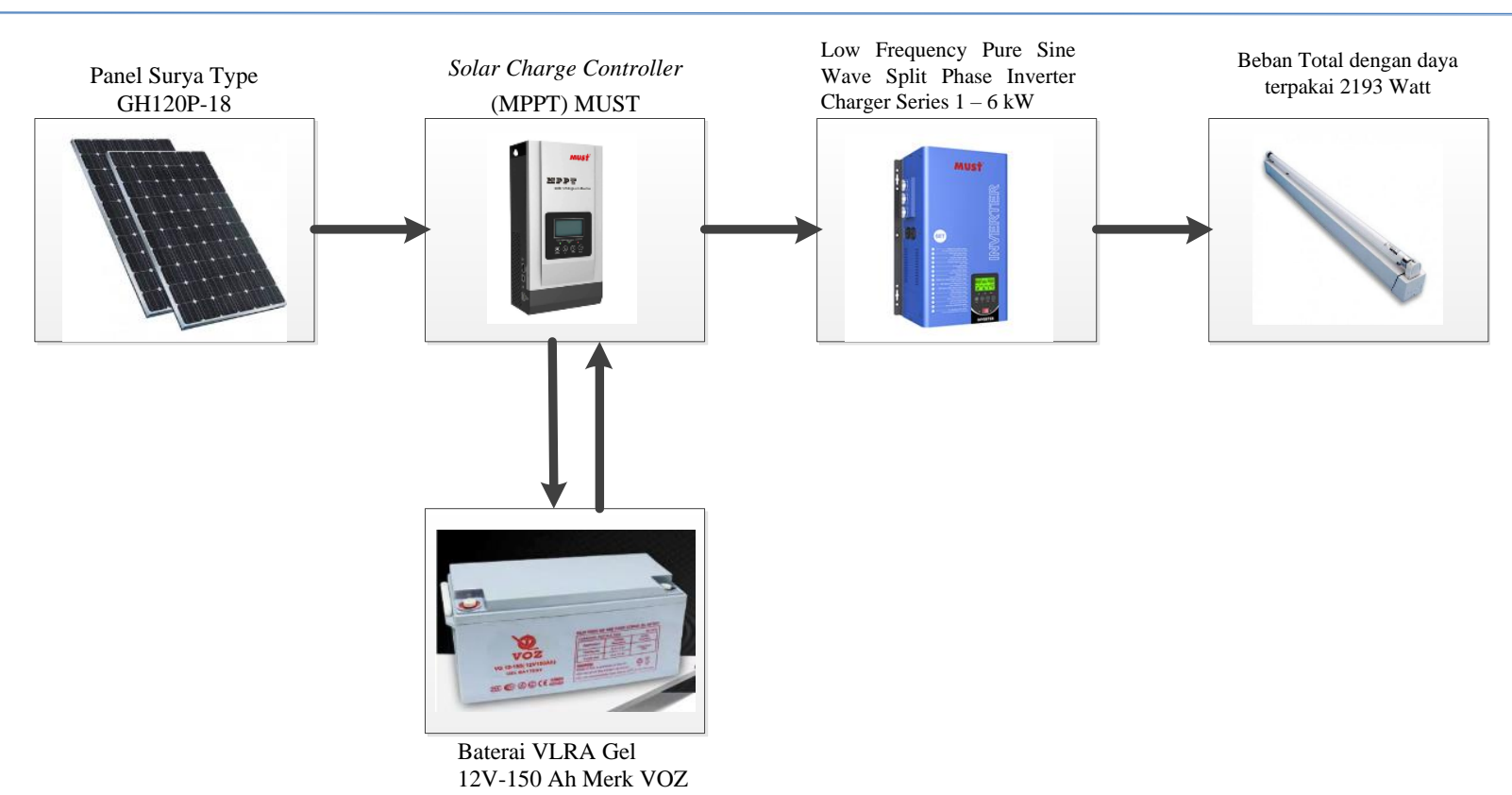

Gambar 5. Model diagram sistem PLTS Off Grid pada gedung Fakultas Teknik Sumber: Pengolahan data, 2021

\section{Total Biaya yang diperlukan untuk Keseluruhan Sistem PLTS}

Total biaya investasi sistem PLTS yang akan dibangun pada Gedung Fakultas Teknik dihitung berdasarkan harga persatuan peralatan yang digunakan. Detail biaya yang dikeluarkan ditampilkan pada Tabel 6.

Tabel 6. Estimasi biaya peralatan PLTS (Off Grid)

\begin{tabular}{|c|c|c|c|c|}
\hline Nama Alat & Spesifikasi & $\begin{array}{l}\text { Harga satuan } \\
\text { (Rp) }\end{array}$ & $\begin{array}{c}\text { Jumlah Alat } \\
\text { (Unit) }\end{array}$ & Total (Rp) \\
\hline $\begin{array}{l}\text { Panel Surya Merk } \\
\text { GH Solar }\end{array}$ & $\begin{array}{l}\text { Model: GH120P-18 } \\
\text { (Polycristalline) } \\
\operatorname{Vmax}\left(\mathrm{V}_{\mathrm{mp}}\right) 18,4 \mathrm{~V} \\
\mathrm{Imax}_{(\mathrm{I}}\left(\mathrm{I}_{\mathrm{mp}}\right) 6,53 \mathrm{~A} \\
\mathrm{~V}_{\mathrm{oc}}: 22,6 \mathrm{~V} \\
\mathrm{I}_{\mathrm{sc}}: 6,98 \mathrm{~A}\end{array}$ & $800.000,-$ & 33 & $26.400 .000,-$ \\
\hline $\begin{array}{l}\text { Solar Charge } \\
\text { Controller }(\mathrm{SCC}) \\
\text { Merk MUST }\end{array}$ & $\begin{array}{l}\text { Tegangan : } 12 / 24 / 36 / 48 \mathrm{~V} \\
\text { Arus : 60/80/100/150/250A } \\
\text { Jenis : MPPT }\end{array}$ & 4.100.000,- & 1 & 4.100.000,- \\
\hline $\begin{array}{l}\text { Baterai VLRA } \\
\text { Gel Merk VOS }\end{array}$ & $\begin{array}{l}\text { Jenis : VRLA Gel tegangan } \\
: 12 \mathrm{~V} \\
\text { Kapasitas : } 150 \mathrm{Ah}\end{array}$ & 3.800.000,- & 41 & 155.800.000,- \\
\hline $\begin{array}{l}\text { Inverter Merk } \\
\text { MUST Type } \\
\text { EP3300 TLV }\end{array}$ & $\begin{array}{l}\text { Low Frequency Pure Sine } \\
\text { Wave }(P W M) \\
\text { Split Phase Inverter } \\
\text { Charger Series daya 1- } \\
6 \mathrm{KW}\end{array}$ & 7.200.000,- & 1 & 7.200.000,- \\
\hline
\end{tabular}

Sumber: Pengolahan data, 2021

Berdasarkan Tabel 6 terlihat nilai total investasi awal yang harus dikeluarkan untuk membangun sistem PLTS pada Gedung Fakultas Teknik sebesar RP. 193.500.000,-. Nilai tersebut belum termasuk biaya pemasangan dan juga biaya preventive maintenance yang harus dilakukan setiap 6 bulan.

\section{Penentuan Kelayakan Penerapan PLTS}

Nilai investasi total yang dibutuhkan untuk instalasi sistem PLTS off grid pada gedung Fakultas Teknik dengan perbandingan nilai penggunaan energi dari PLN saat ini masih dalam katagori layak untuk perkiraan penggunaan maksimal dalam jangka waktu 20 tahun. Beberapa peralatan yang dapat ditentukan berdasarkan perhitungan diantaranya panel surya jenis polycristalline 33 unit, Solar Charge Controller 
MPPT) 12V-250A, baterai jenis VLRA Gel 12V-150 Ah 41 buah, Inverter Low Frequency Pure Sine Wave (PWM) Split Phase Inverter Charger Series daya 1-6 KW.

Hasil perhitungan Total Energi (TE) pada gedung sebesar 20,422 kWh/hari, dan berdasarkan nilai tersebut dibutuhkan sebanyak 33 unit panel surya untuk menyuplai daya listrik pada gedung tersebut. Jumlah tersebut merupakan nilai aman untuk mendukung system off grid yang akan dibangun. Beberapa faktor yang menjadi pertimbangan diantaranya spare energy dan juga losses yang mungkin terjadi di beberapa titik seperti pada terminal panel surya, perkabelan dan kotoran pada permukaan panel itu sendiri. Selain panel surya, peralatan lainnya yang ikut diperhitungkan adalah Solar Charge Controller. Alat ini merupakan pusat dari system control off grid, dimana energi yang dihasilkan panel surya disimpan pada baterai melalui alat ini untuk selanjutnya digunakan sebagai sumber charging baterai. Lama masa pakai unit baterai sangat tergantung dari Solar Charge Controller, dengan kondisi baterai terus menerima arus yang besar tanpa pembatas dan pengatur maka dapat dipastikan baterai akan cepat rusak. Oleh karena itu kondisi baterai harus diperhatikan dengan baik, dan salah satu caranya adalah dengan menggunakan Solar Charge Controller yang sesuai dengan kapasitas produksi energi dari panel surya. Jenis Solar Charge Controller yang cocok digunakan pada instalasi PLTS pada Gedung Fakultas Teknik adalah menggunakan jenis (MPPT) 12V-250A. Jenis ini digunakan dengan pertimbangan nilai arus yang dapat digunakan SCC cukup besar atau diatas nilai maksimum sistem sebesar $215 \mathrm{~A}$.

Selain itu untuk untuk mendukung sistem agar dapat bertahan selama 3 hari masa outonomy day (estimasi bila sinar matahari tidak bersinar sepenuh hari), maka digunakan baterai VLRA Gel 12V-150 Ah sebagai media storage. Jenis baterai VLRA dapat bekerja lebih baik dibanding jenis baterai lead acid atau lainnya, kondisi ini karena baterai VLRA dapat melakukan charge - discharge hingga kedalaman 50\% dari kapasitas tersedia dan tidak mengakibatkan baterai rusak. Proses charge - discharge tersebut juga dikenal dengan istilah Deep of Discharge (DoD), dan merupakan faktor yang sangat diperhatikan pada sistem instalasi PLTS off grid. Kondisi ini karena sistem off grid sangat tergantung pada baterai, dan bila baterai tidak handal akan mengakibatkan system blank out. Jika terjadi blank out lebih cepat dari perkiraan outonomy day, maka sistem tersebut dianggap gagal. Pemilihan baterai dengan kapasitas $150 \mathrm{Ah}$ telah disesuaikan dengan nilai Total Energi (TE) berdasarkan nilai beban keseluruhan pada Gedung Fakultas Teknik. Nilai TE yang digunakan adalah nilai maksimal beban harian yang dipakai dalam waktu maksimal perhari per beban. Peralatan lainnya yang menjadi tinjauan perencanaan ini adalah inverter yang berfungsi untuk mengkonversi arus listrik dari arus searah Direct Current DC menjadi Alternating Current AC.

Untuk sistem PLTS off grid yang menggunakan jenis beban AC seperti lampu, air conditioner (AC), motor listrik dan Televisi sangat membutuhkan inverter. Sistem yang direncanakan ini menggunakan inverter jenis Pure Sine Wave (PSW) frekuensi rendah dengan pertimbangan beban yang digunakan pada gedung cukup beragam dan memerlukan daya yang cukup besar sehingga jenis PSW sangat sesuai untuk digunakan.

\section{Kesimpulan}

Hasil penelitian dan simulasi perhitungan yang telah dilakukan, dapat ditarik kesimpulan bahwa total daya eksisting yang digunakan pada Gedung Fakultas Teknik selama ini sebesar 2.193 W/hari, dan saat dikalikan dengan lama waktu penggunaan beban diperoleh besaran energi yang digunakan sebesar $20.422 \mathrm{Wh} /$ hari. Berdasarkan jumlah Energi Total (TE) per hari, ditentukan jumlah panel surya yang dibutuhkan untuk menangani beban eksisting yaitu sebanyak 33 unit. Untuk menyesuaikan jumlah kebutuhan beban, maka digunakan jenis panel surya dengan kapasitas daya $120 \mathrm{Wp}$. Selain panel, ditentukan juga peralatan pendukung lainnya untuk membangun sistem PLTS off grid diantaranya; Solar Charge Controller (SCC) tegangan 12V-arus 250A jenis MPPT, Pure Sine Wave (PSW) sebanyak 1 unit, Baterai VRLA Gel 12V kapitas 150 Ah sebanyak 41 unit, dan inverter Low Frequency Pure Sine Wave $(P W M)$ Split Phase Inverter Charger Series daya $1-6 \mathrm{~kW}$ sebanyak 1 unit. Model instalasi panel surya yang diterapkan pada Gedung Fakultas Teknik menggunakan sistem off grid dengan masa outonomy day 3 hari. Instalasi jenis ini tidak membutuhkan PLN sebagai backup energi listrik, dan satu-satunya sumber arus berasal dari baterai.

\section{Ucapan Terima Kasih}

Penelitian ini dibiayai oleh Universitas Teuku Umar (Kementerian Pendidikan, Kebudayaan, Riset dan Teknologi) sesuai dengan Surat Perjanjian Penugasan Pelaksanaan Penelitian Asisten Ahli Tahun Anggaran 2021 Nomor: 031/UN59.7/PT.01.03/2021. 


\section{Referensi}

[1] G. H. Sihotang, "Perencanaan Pembangkit Listrik Tenaga Surya Rooftop di Hotel Kini Pontianak."

[2] S. Ali and T. . Aziz Pandria, "Penentuan Sudut Kemiringan Optimal Panel Surya Untuk Wilayah Meulaboh," J. Mekanova Mek. Inov. dan Teknol., vol. 5, no. 1, pp. 21-29, 2019, doi: 10.35308/jmkn.v5i1.1621.

[3] L. Adam, "Dinamika Sektor Kelistrikan di Indonesia: Kebutuhan dan Performa Penyediaan Dynamics of Electricity Sector In Indonesia: The Needs And Performance of Supply," pp. 29-41, 2011.

[4] Gita Amanda, "PLN Meulaboh Segera Aliri Listrik ke Desa Sikundo," www.republika.co.id, 2019. https://www.republika.co.id/berita/ekonomi/korporasi/19/02/12/pmt8na423-pln-meulaboh-segeraaliri-listrik-ke-desa-sikundo.

[5] H. Suyanto, "Kajian Potensi Energi Surya Di Provinsi Nusa Tenggara Barat," Issn 1979-0783, vol. 8, p. 2, 2016.

[6] T. M. A. Pandria, "Optimalisasi Penggunaan Energi Listrik Pada Fakultas Teknik Universitas Serambi Mekkah Menggunakan Metode Genetik Algoritma," vol. IV, no. 13, 2019.

[7] R. Ikhsan, I. D. Sara, and R. S. Lubis, "Studi Kasus Kelayakan Penerapan Sistem Hybrid Building Applied Photovoltaics (BAPV)-PLN pada Atap Gedung Politeknik Aceh," J. Rekayasa Elektr., vol. 13, no. 1, p. 48, 2017, doi: 10.17529/jre.v13i1.6071.

[8] Muzakkir, "2018, Pelamar UTU Mencapai 6.562 Orang, Daya Tampung 1.670 Mahasiswa," utu.ac.id, 2018. http://utu.ac.id/posts/read/2018-pelamar-utu-mencapai-6562-orang-daya-tampung1670-mahasiswa.

[9] T. M. A. Pandria and E. Mawardi, "Penentuan Sudut Kemiringan Optimum Berdasarkan Energi Keluaran Panel Surya," vol. VI, no. 1, pp. 1655-1661, 2021.

[10] J. Windarta, E. Wista Sinuraya, A. Zaenal Abidin, A. Era Setyawan, and Angghika, "Perancangan Pembangkit Listrik Tenaga Surya ( PLTS ) Berbasis Homer Di SMA Negeri 6 Surakarta Sebagai Sekolah Hemat Energi Dan Ramah Lingkungan," Pros. Semin. Nas. MIPA 2019 Univ. Tidar, pp. 21-36, 2019.

[11] M. Naim, "Rancangan Sistem Kelistrikan Plts Off Grid 1000 Watt Di Desa Loeha Kecamatan Towuti," Vertex Elektro, vol. 12, no. 1, pp. 17-25, 2020, [Online]. Available: https://journal.unismuh.ac.id/index.php/vertex/article/view/4013.

[12] R. Sitepu and A. Gunadhi, "Kajian Potensi Pembangkit Listrik Tenaga Surya pada Atap Gedung Kota Surabaya : Studi Kasus Gedung Perkuliahan," pp. 150-154.

[13] PVsyst, "PVsyst," www.pvsyst.com, 2021. https://www.pvsyst.com/support/ (accessed Oct. 05, 2021).

[14] H. Judul, "Analisis Tekno-Ekonomi Pembangkit Listrik Tenaga Surya ( PLTS ) di PT. Pertamina (Persero )," 2016.

[15] Janaloka, "No Title," analoka.com, 2021. https://janaloka.com/fungsi-solar-charger-controllerpada-sistem-panel-surya/ (accessed Sep. 01, 2021). 